University of Nebraska - Lincoln

DigitalCommons@University of Nebraska - Lincoln

Agronomy \& Horticulture -- Faculty Publications

Agronomy and Horticulture Department

1998

\title{
Tolerance and velvetleaf (Abutilon theophrasti) suppressive ability of two old and two modern corn (Zea mays) hybrids
}

John L. Lindquist

University of Nebraska-Lincoln, jlindquist1@unl.edu

David A. Mortensen

University of Nebraska-Lincoln, dmortensen@unl.edu

Follow this and additional works at: https://digitalcommons.unl.edu/agronomyfacpub

Part of the Plant Sciences Commons

Lindquist, John L. and Mortensen, David A., "Tolerance and velvetleaf (Abutilon theophrasti) suppressive ability of two old and two modern corn (Zea mays) hybrids" (1998). Agronomy \& Horticulture -- Faculty Publications. 620.

https://digitalcommons.unl.edu/agronomyfacpub/620

This Article is brought to you for free and open access by the Agronomy and Horticulture Department at DigitalCommons@University of Nebraska - Lincoln. It has been accepted for inclusion in Agronomy \& Horticulture -Faculty Publications by an authorized administrator of DigitalCommons@University of Nebraska - Lincoln. 


\section{Tolerance and velvetleaf (Abutilon theophrasti) suppressive ability of two old and two modern corn (Zea mays) hybrids}

\author{
John L. Lindquist \\ Corresponding author. University of Nebraska, \\ Lincoln, NE 68583-0915; jlindquist@unl.edu
}

David A. Mortensen

University of Nebraska, Lincoln, NE 68583-0915
Improved crop tolerance and weed suppressive ability are tactics that may reduce the negative effect of weeds on crop yield. Irrigated field experiments were conducted to compare leaf area index (LAI), intercepted photosynthetic photon flux (PPF), and relative tolerance and velvetleaf suppressive ability among two old (circa 1940) and two modern corn hybrids. Each hybrid was grown in monoculture and in mixture with velvetleaf at $1,4,16$, and 40 plants $\mathrm{m}^{-1}$ row. Plants were periodically harvested in monoculture plots to obtain estimates of corn LAI, and PPF interception was measured. Variation in hybrid tolerance to velvetleaf competition for light was evaluated by comparing among hybrids the coefficients of a regression of corn yield loss on velvetleaf density. Velvetleaf seed capsule production in the presence of each hybrid was compared to evaluate variation in velvetleaf suppressive ability among hybrids. Maximum corn yield loss was $32 \%$ lower for the two old hybrids, and velvetleaf capsule production was reduced by $62 \%$ at low velvetleaf densities in 1995 compared to the modern hybrids. In 1996, yield loss of the modern hybrid 3394 was $74 \%$ lower than that of the other three hybrids at low velvetleaf densities, whereas maximum yield loss of the old hybrid 336 was $44 \%$ lower at high densities. Velvetleaf capsule production did not vary among hybrids at any velvetleaf density in 1996. Hybrids with greater tolerance and velvetleaf suppressive ability also had greater LAI and PPF interception, suggesting optimized corn LAI and PPF interception may be useful in an integrated weed management program.

Nomenclature: Velvetleaf, Abutilon theophrasti L., ABUTH; corn, Zea mays L. 'Pioneer 336, 344, 3379, and 3394'.

Key words: Competition, competitive ability, plant stress, integrated weed management, ABUTH.
Improved crop tolerance and weed suppressive ability (crop competitiveness) are tactics that may reduce the negative effect of weeds on crop yield (Callaway 1990; Forcella 1987; Jordan 1993; Lindquist and Kropff 1996; Wicks et al. 1986). The distinction between crop tolerance and weed suppressive ability is important for identifying these characteristics. Improved crop tolerance results in a higher yield, relative to weed-free yield, at a given weed infestation. This definition of crop tolerance includes both avoidance and tolerance in the strict sense. Avoidance refers to an ability to escape the effect of a stress factor (Levitt 1980). For example, a crop that acquires soil resources from a different zone of the rhizosphere than the weed is avoiding interference. Tolerance in the strict sense refers to an ability to endure competitive stress from the weed without substantial reduction in growth or yield. In cases where both crop and weed demand the same resources on a similar time scale, crop tolerance may be the direct result of resource preemption by the crop (Jordan 1993). An example of resource preemption is a crop with canopy architecture that allows it, when competing for light, to intercept a higher fraction of the total incoming photosynthetic photon flux (PPF). This type of crop tolerance may also result in improved weed suppressive ability. Crop tolerance will not improve long-term management of weed populations unless weed seed production also is reduced. However, weed-tolerant crops will improve yield stability in weedy fields.

Improved weed suppressive ability reduces weed seed pro- duction and therefore can improve long-term weed management. Improved weed suppressive ability does not, however, ensure crop tolerance (Jordan 1993). Improved suppressive ability with a reduction in tolerance could occur as a result of trade-offs in allocation patterns. For example, onset of competition for light may signal an increase in carbon allocation to leaf area within the crop. This change may result in a reduction in light available to the weed but also in a reduction in crop harvest index, and therefore yield. In a widely cited study in rice (Oryza sative L.), Jennings and Aquino (1968) suggested that crop height and leafiness were positively correlated with competitive ability but negatively correlated with yield potential, presumably resulting from trade-offs in allocation patterns. However, recent research has shown that strongly competitive, high-yielding wheat (Triticum aestivum L.) cultivars may reduce the longterm cost of controlling rigid ryegrass (Lolium rigidum Gaudin) in Australia (Lemerle et al. 1996).

Several researchers have shown that increased corn population density and narrow row spacing may increase LAI and PPF interception (McLachlan et al. 1993; Murphy et al. 1996; Ottman and Welch 1989; Tetio-Kagho and Gardner 1988; Williams et al. 1968). Under conditions where weed-crop competition is primarily for light, it is reasonable to assume that a corn canopy that intercepts more PPF may also be more tolerant and weed suppressive. McLachlan et al. (1993) showed that high corn population density reduced redroot pigweed (Amaranthus retroflexus L.) biomass 
up to $89 \%$ compared to lower corn density. Tollenaar et al. (1994a) showed that yield loss under high and low weed pressure was reduced by 50 and $81 \%$ when corn population density was increased from 4 to 10 plants $\mathrm{m}^{-2}$. Murphy et al. (1996) further showed that increased corn density and narrow row spacing reduced the biomass of a composite population of late emerging weeds by up to $41 \%$. Reducing row spacing from 0.76 to $0.5 \mathrm{~m}$ reduced yield loss from 15 to $2 \%$ (Murphy et al. 1996). These experiments show that modifying cultural practices to optimize LAI and PPF interception can have a positive influence on corn tolerance and weed suppressive ability.

Several recent reviews have documented variation among crop genotypes in their response to weed competition and capacity for suppressing weed growth rate and seed production (Berkowitz 1988; Callaway 1990; Callaway and Forcella 1992; Jordan 1993). Staniforth (1961) showed that an early-maturing corn hybrid was more tolerant to high yellow foxtail [Setaria glauca (L.) Beauv.] densities than a late-maturing hybrid, suggesting that the observed tolerance was the result of avoidance. Tollenaar et al. (1994b) showed that four corn hybrids differed in their yield response to interference from a composite population of weeds, indicating that corn tolerance to weeds can vary among hybrids. However, weed biomass at corn silking did not vary among hybrids, suggesting that these hybrids did not vary in their weed suppressive ability (Tollenaar et al. 1994b).

The objectives of this research were to compare LAI and intercepted PPF at various stages of development among four corn hybrids grown under weed-free conditions and evaluate whether differences in tolerance and weed suppressive ability can be detected among the four hybrids.

\section{Materials and Methods}

\section{Field Experiments}

Experiments were conducted in adjacent fields at the University of Nebraska Agricultural Research and Development Center near Mead, NE ( $41^{\circ} 14^{\prime} \mathrm{N}, 96^{\circ} 29^{\prime} \mathrm{W} ; 368.7 \mathrm{~m}$ above sea level), in 1995 and 1996. Soil was a Sharpsburg silty clay loam (fine, montmorillonitic mesic Typic Argiudolls) with $3.5 \%$ organic matter. Experiments were designed as randomized complete blocks with four replicates. Within a block, five corn hybrid treatments were combined in a partial factorial with five velvetleaf density treatments $(0,1$, 4, 16, and 40 plants $\mathrm{m}^{-1}$ row). Hybrid treatments included no hybrid (velvetleaf monoculture), two old hybrids (336 1 and 344, released in 1940 and 1945, respectively), and two modern hybrids (3379 and 3394). The old hybrids were generally taller and had greater per-plant leaf area, more leaf area near the top of the plant, less erect leaf angle distribution (Lindquist 1997), and leaves with a darker hue of green (which may influence leaf reflectance). All hybrids reached physiological maturity on September 16 in both 1995 and 1996. All hybrids reached anthesis on July 28 in 1995, whereas the two old hybrids reached anthesis about $4 \mathrm{~d}$ later than the two modern hybrids in 1996 (July 23 and July 28, respectively). Greater interplant variation was observed in the time of pollen shed and silking of the two old hybrids than for the modern hybrids. Duvick (1992) described morphological characteristics and yield of the two old hybrids relative to many other Pioneer hybrids.
Each experimental unit was a six-row $(0.76 \mathrm{~m}$ apart) by 14-m long plot. Soybean [Glycine $\max$ (L.) Merr.] was grown in the year prior to establishment of each study. Fields were tandem disked and field cultivated to prepare the seedbed in spring. Corn was seeded ${ }^{2}$ on May 19 and 7 to obtain overall mean densities of $5.56( \pm 0.60)$ and 4.27 $( \pm 0.69)$ plants $\mathrm{m}^{-2}$ in 1995 and 1996 , respectively. Velvetleaf was seeded directly into the crop row using a push planter on May 22 and 14 and thinned to target densities on July 5 and June 19 in 1995 and 1996, respectively. Corn and velvetleaf both reached $50 \%$ emergence on May 29 and 19, 1995 and 1996, respectively. Dry ammonium nitrate was broadcast at $110 \mathrm{~kg} \mathrm{~N} \mathrm{ha}^{-1}$ prior to planting in 1995 , and anhydrous ammonia was applied in fall (1995) at 100 $\mathrm{kg} \mathrm{N} \mathrm{ha}^{-1}$ for the 1996 experiment. Grass weeds were controlled with a preemergence broadcast application of alachlor at $0.42 \mathrm{~kg}^{2} \mathrm{ha}^{-1}$ in each year. Other weeds were controlled with cultivation (on June 22, 1995, and June 18, 1996) and removed by hand as needed. Plots were sprinkler irrigated weekly beginning on July 11 in both 1995 and 1996.

Two plants were periodically harvested from each monoculture corn plot, leaves were separated, and green leaf area was measured using an area meter. ${ }^{3}$ Plants selected for harvest were located in the second and fifth rows of each plot and were at least $1 \mathrm{~m}$ from the location of any previously harvested plant. Estimates of corn and velvetleaf density were obtained by counting the number of plants in a 3.65$\mathrm{m}$ section of row in each of the middle two rows of a plot on July 26 and 30 in 1995 and 1996, respectively. Leaf area index (LAI) at each sampling date was estimated as the product of leaf area per plant and number of plants per square meter. Quantity of PPF intercepted by the canopy was measured periodically under full-sun conditions at two locations in each monoculture corn plot. Incident PPF above the canopy $\left(I_{\mathrm{o}}\right)$ was measured using a point quantum sensor ${ }^{4}$ mounted on a $3-\mathrm{m}$ staff. PPF at the soil surface $\left(I_{s}\right)$ was measured using a $1-\mathrm{m}$ line quantum sensor ${ }^{5}$ placed perpendicular to and centered on the crop row. Intercepted PPF was integrated over a single 5-s period for each measurement. All measurements were made between 10:00 A.M. and 2:00 P.M. on each date to minimize the influence of solar zenith angle on PPF attenuation. Intercepted PPF was estimated as $1-I_{\mathrm{s}} / I_{\mathrm{o}}$. This approach may result in an underestimate of actual PPF interception, but it is reasonable to assume that comparisons of intercepted PPF among hybrids are valid. Three rows of each plot were combine harvested, the grain was weighed on the combine, and a subsample was kept for moisture determination. Yield $\left(\mathrm{kg} \mathrm{ha}^{-1}\right)$ was then corrected to $15.5 \%$ moisture content. Velvetleaf seed production was estimated by harvesting six plants per plot after complete leaf dry down and counting the total number of seed capsules produced per plant.

Corn and velvetleaf development stage (DVS) was made more comparable across years by defining phenological time using a dimensionless scale ranging from 0 (emergence) to 1.0 (anthesis) to 2.0 (physiological maturity). Rate of development was calculated as the inverse of the number of degree days accumulated between two phenological events. Growing degree days accumulated per day $\left(\mathrm{GDD}_{t}\right)$ after emergence were obtained using (Kropff and van Laar 1993): 


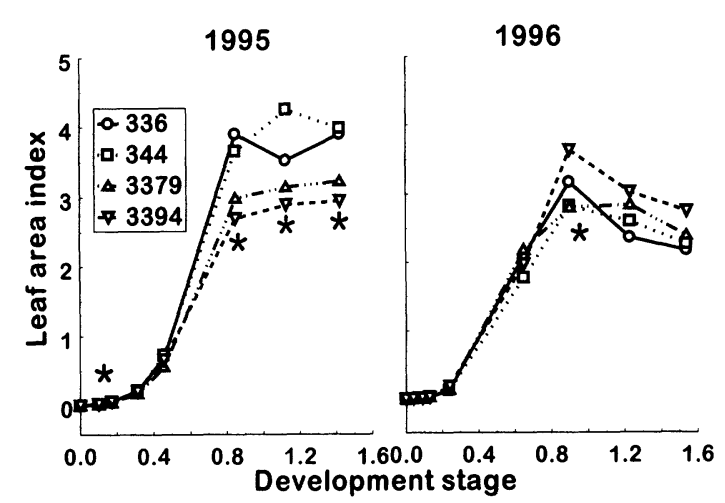

Figure 1. Leaf area index of two old (Pioneer Brand 336 and 344) and two modern (Pioneer Brand 3379 and 3394) corn hybrids in 1995 and 1996. An asterisk indicates that differences $(P<0.05)$ among hybrids occurred at that sampling time.

$$
\mathrm{GDD}_{t}=\min \left(\left(30-T_{\mathrm{b}}\right),\left(\frac{T_{\max }+T_{\min }}{2}-T_{\mathrm{b}}\right)\right)
$$

where $T_{\max }$ and $T_{\min }$ are maximum and minimum temperatures occurring on day $t . T_{\mathrm{b}}$ is base temperature for development (10 C for both corn and velvetleaf), and 30 is the maximum temperature for development. Minimum and maximum daily temperatures were obtained from an automated weather station located approximately $1 \mathrm{~km}$ from the experimental site.

\section{Quantification of Tolerance and Velvetleaf Suppressive Ability}

Cousens (1985) showed that crop yield loss could be accurately related to weed density using a rectangular hyperbola equation:

$$
Y_{\mathrm{L}}=\frac{I \cdot N}{1+\frac{I \cdot N}{A}}
$$

where $Y_{\mathrm{L}}$ is percent yield loss, $N$ is weed density, $I$ is percent yield loss as weed density approaches zero, and $A$ is the upper asymptote, or maximum percent yield loss. Estimates of $I$ and $A$ have been shown to vary among experiments conducted across years and locations (Lindquist et al. 1996; Lotz et al. 1996; Swinton et al. 1994). However, estimates of $I$ and $A$ have not been compared among corn hybrids, holding all other factors constant. We assume variation in tolerance exists if the fit of Equation 2 varies among hybrids within a year (Cousens and Fletcher 1990). Velvetleaf seed capsule production in the presence of the four hybrids was compared by regressing number of capsules produced per plant $(S)$ on velvetleaf density $(N)$ using an exponential equation:

$$
S=a \exp (-b N)
$$

where $a$ is the intercept and $b$ is the slope.

\section{Statistical Analyses}

Mean LAI and PPF were compared among hybrids for each sampling date using contrast analysis. Yield loss and velvetleaf seed capsule production as a function of velvetleaf

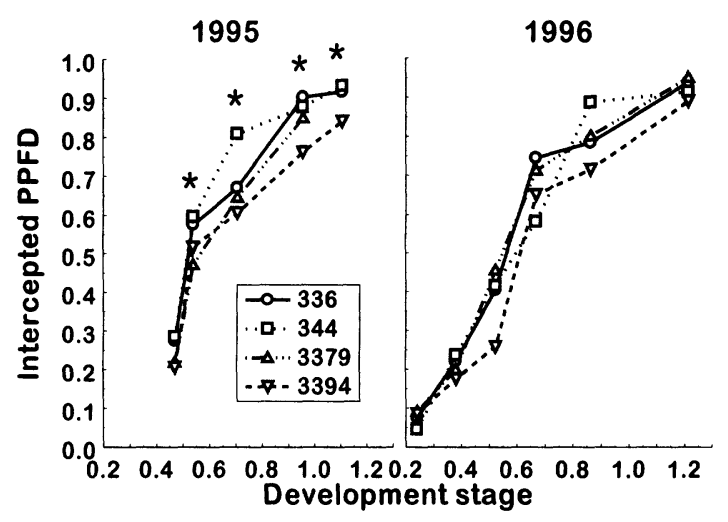

FIGURE 2. Intercepted PPF of two old (Pioneer Brand 336 and 344) and two modern (Pioneer Brand 3379 and 3394) corn hybrids in 1995 and 1996. An asterisk indicates that differences $(P<0.05)$ among hybrids occurred at that sampling time.

density were compared among the four corn hybrids in each year. Yield loss was calculated as yield at a given velvetleaf density $(N)$ divided by mean weed-free yield. Equations 2 and 3 were then fit to yield loss and velvetleaf seed capsule production, respectively, and coefficient estimates compared among hybrids using the extra sum of squares procedure for nonlinear regression described by Lindquist et al. (1996) and Ratkowsky (1983).

\section{Results and Discussion}

\section{Leaf Area Index}

Weed-free LAI of the modern hybrid 3379 was lower than that for 3394 and 344 at a development stage (DVS) of 0.10 (June 6) and 0.17 (June 13) in 1995 but did not differ from hybrid 336 (Figure 1). No differences in LAI occurred during early growth in 1996. Leaf area index began to approach an asymptote at DVS $=0.85$ (July 20) in 1995 with the two old hybrids being greater $(3.78 \pm 0.32)$ than the two modern hybrids $(2.85 \pm 0.32)$. The two old hybrids maintained greater LAI through the final sampling date at DVS $=1.42$ (August 16). Maximum LAI was measured at DVS $=0.90$ (July 17) in 1996 (Figure 1), the only sampling time when differences in LAI were detected among hybrids. The modern hybrid 3394 had higher LAI $(3.61 \pm 0.15)$ than 344 or $3379(2.81 \pm 0.15)$ but did not differ from 336 (3.17 \pm 0.15$)$. LAI was generally lower for all hybrids in 1996 compared with 1995 because corn density was lower in 1996.

\section{Intercepted PPF}

The modern hybrid 3379 intercepted less PPF (47\%) than 344 or $336(59 \%)$ but did not differ from 3394 (52\%) at DVS $=0.54$ (July 5) in 1995 (Figure 2). The old hybrid 344 had greatest PPF interception (81\% compared with $64 \%$ ) at DVS $=0.71$ (July 13). The modern hybrid 3394 intercepted less (76 and 87\%) PPF than the other three hybrids (84 and 93\%) at DVS $=0.96$ (July 25) and 1.11 (August 2) in 1995. Differences in the quantity of PPF intercepted among the four hybrids were not detected in 1996 (Figure 2). Hybrids with larger LAI generally intercepted a greater fraction of incoming PPF in 1995, but not in 1996. Maximum PPF interception of all hybrids did not differ 
TABLE 1. Estimates of $I$ and $A$ obtained from fitting Equation 2 to yield loss of the four hybrids in each year. ${ }^{\mathrm{a}}$

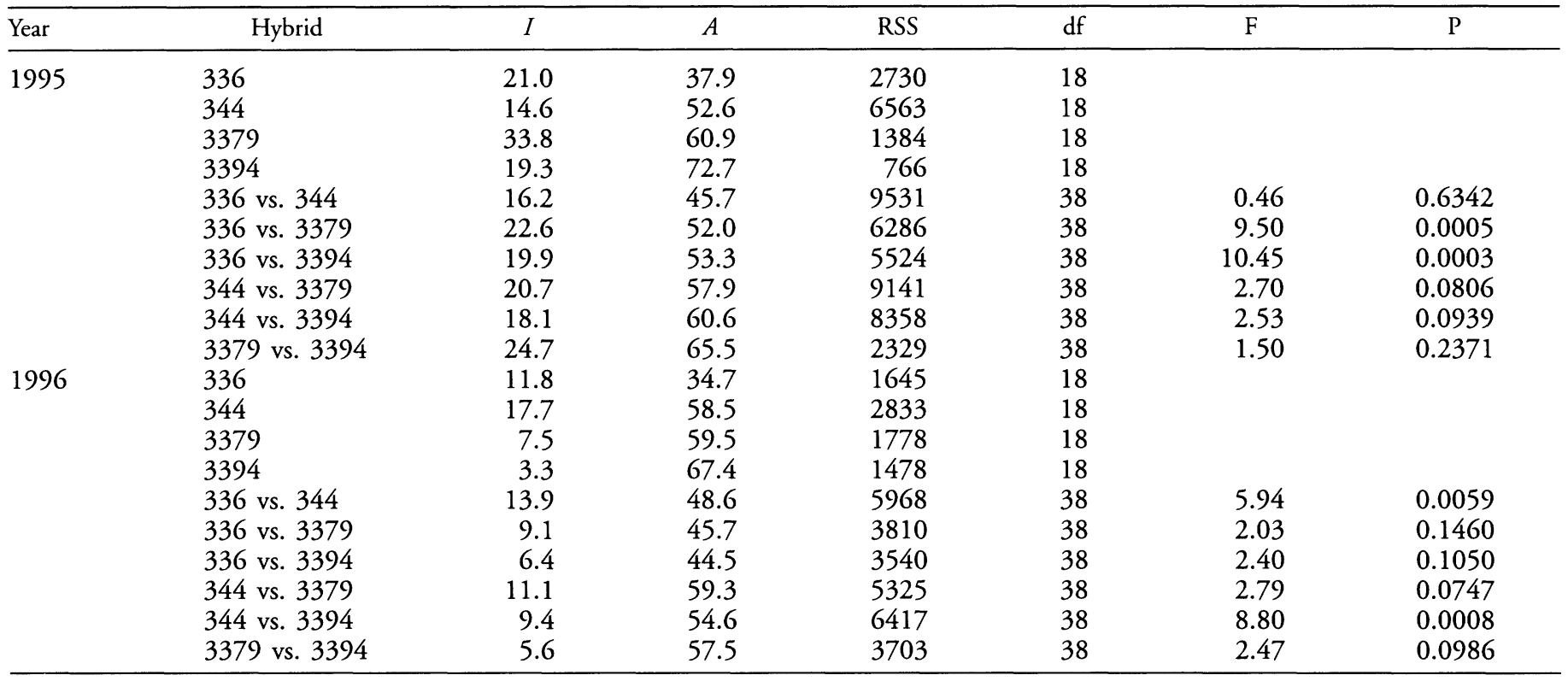

a $I$, yield loss as weed density approaches zero; $A$, maximum yield loss; RSS, residual sums of squares of the regression; $\mathrm{df}$, degrees of freedom; $\mathrm{F}$, the $\mathrm{F}$ statistic calculated for the contrast; $\mathrm{P}$, probability that model coefficients differ between each pair of hybrids.

between years (90 and $92 \%$ in 1995 and 1996 , respectively). Hence, although canopy LAI was lower in 1996, it was not low enough to influence overall radiation interception late in the season. However, the time at which maximum interception was reached did not necessarily correspond to the time maximum LAI was reached (Figures 1 and 2), suggesting that other canopy characteristics (canopy height, vertical leaf area distribution, extinction coefficient, and leaf reflectance) were important in determining PPF interception.

\section{Variation in Weed-Free Yield}

Weed-free corn yield varied among hybrids in each year of this study. The modern hybrids 3394 and 3379 produced highest yields $\left(6,975\right.$ and $9,176 \mathrm{~kg} \mathrm{ha}^{-1}$ in 1995 and 1996 , respectively). Weed-free yields of 336 and 344 differed (4,597 and 4,021 kg ha ${ }^{-1}$, respectively) in 1995 but did not differ in $1996\left(6,219 \mathrm{~kg} \mathrm{ha}^{-1}\right)$. Yields of all hybrids were greater in 1996 than 1995. The lower yields in 1995 may

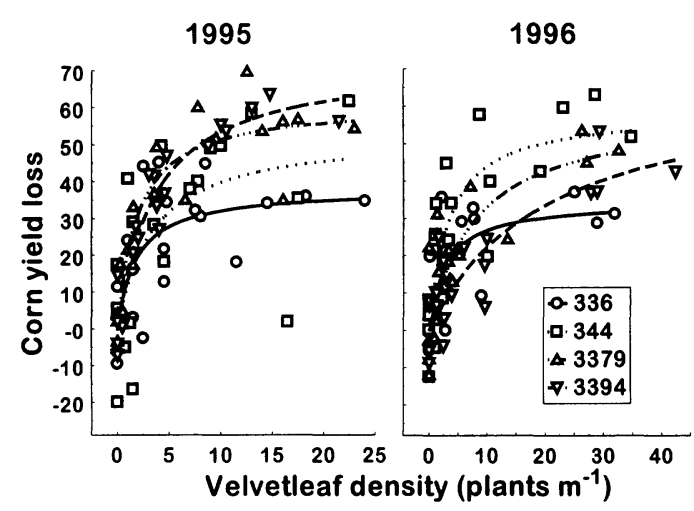

FIGURE 3. Percent corn yield loss as a function of velvetleaf density for two old (Pioneer Brand 336 and 344) and two modern (Pioneer Brand 3379 and 3394) corn hybrids in 1995 and 1996. have resulted from later planting followed by substantial heat stress (temperatures $>38 \mathrm{C}$ ) during early August.

\section{Variation in Tolerance to Velvetleaf}

Differences in tolerance to velvetleaf by Equation 2 were observed among the four hybrids in each year (Table 1 ). Yield loss-weed density relationships did not differ between the two old or between the two modern hybrids in 1995 (Table 1). However, these relationships did differ between the old and the modern hybrids, indicating that the two old hybrids were more tolerant of velvetleaf than the modern hybrids in 1995. Maximum yield loss of the two old hybrids (336 and 344) was $32 \%$ lower than that for the two modern hybrids in 1995 (Figure 3). Hybrids having greater tolerance also had greatest LAI and PPF interception in 1995, suggesting that these traits may contribute to increased corn tolerance to velvetleaf.

Yield loss-velvetleaf density relationships varied among hybrids in 1996, but an interaction between hybrid and velvetleaf density was evident (i.e., relationships in Figure 3 are not parallel). Hybrid 3394 was most tolerant to velvetleaf competition at low velvetleaf density and had greatest maximum LAI in 1996. The leaf area index of $336 \mathrm{did} \mathrm{not}$ differ from that of 3394 and was most tolerant at high velvetleaf density. Results suggest that LAI may contribute to differences in tolerance to velvetleaf in 1996. However, intercepted PPF does not. Two factors may contribute to the inconsistency between tolerance and PPF interception in 1996. First, PPF interception was greater at earlier development stages in 1995 compared with 1996, suggesting that time course of PPF interception may be more important than the quantity of light intercepted at maximum canopy. Second, leaf area dynamics within the canopy influences vertical PPF interception and therefore may be more important under conditions where canopy LAI is lower than optimum (Lindquist 1997). 


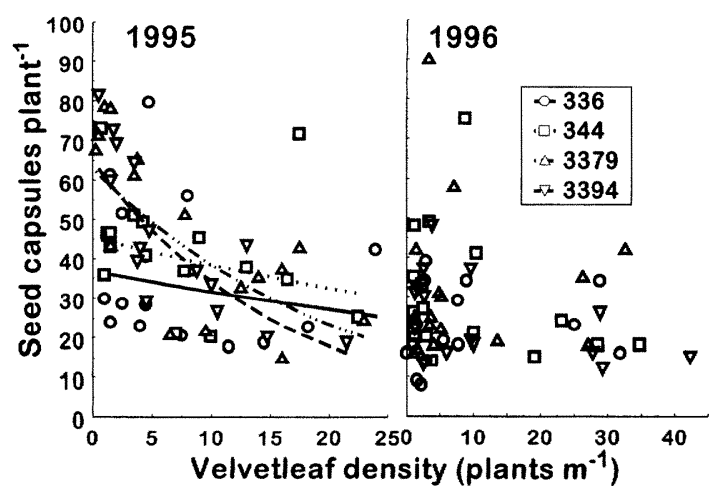

FigURE 4. Number of velvetleaf capsules produced (plant ${ }^{-1}$ ) as a function of velvetleaf density in the presence of two old (Pioneer Brand 336 and 344) and two modern (Pioneer Brand 3379 and 3394) corn hybrids in 1995 and 1996.

\section{Variation in Velvetleaf Suppressive Ability}

Velvetleaf suppressive ability varied among the four hybrids in 1995, but not in 1996. Number of velvetleaf seed capsules produced per plant as velvetleaf density approached zero was nearly twice as large $(72 \pm 6)$ in the presence of 3379 and 3394 than in the presence of 336 and 344 (44 \pm 7 , Figure 4, statistical comparisons not shown). Intraspecific competition between velvetleaf plants became more important than interspecific competition at high velvetleaf densities because capsule production did not differ regardless of which hybrid was present $(30 \pm 4$, Figure 4). Reduced seed production in the presence of the two old hybrids in 1995 indicates that these hybrids were more weed suppressive than the modern hybrids in that year. These differences may be due, in part, to the differences in LAI and PPF interception between the old and modern hybrids. Velvetleaf capsule production did not vary as a function of velvetleaf density or among hybrids in 1996 . Overall mean capsule production was $29( \pm 18)$ capsules plant $^{-1}$ (Figure 4). Lack of variability in velvetleaf suppressive ability in 1996 may result from the lower LAI and intercepted PPF during early stages of grain development in that year.

\section{Application to Weed Management}

The ranking of hybrids in their ability to suppress velvetleaf seed production was similar to their ranking of relative tolerance in 1995. The hybrid with greatest yield relative to weed-free yield also resulted in the lowest velvetleaf seed production at low weed densities. In 1996, differences were observed among hybrids in their relative tolerance, but no differences in relative suppressive ability were measured.

Our results (Table 1 and Figure 3 ) indicate that differences in tolerance to velvetleaf can be detected among morphologically different corn hybrids. Variation in corn tolerance and velvetleaf suppressive ability may result from differences in LAI among hybrids and between years and from the influence of LAI on PPF interception. These results and those of other workers (McLachlan et al. 1993; Murphy et al. 1996; Tollenaar et al. 1997) suggest that the effect of weeds on crop yield can be reduced by modifying a corn canopy to optimize light interception. Optimizing canopy light interception may be accomplished by modifying cultural practices such as row spacing or density or through cultivar selection. However, further analysis is needed to understand why relative tolerance varied between years. An analysis of the relationship between morphological traits and plant performance in mixture may be useful for identifying corn traits that most strongly influence relative yield and weed seed production and at what time during the growing season these traits are most important. Such an analysis will be reported elsewhere (Lindquist et al. 1998).

Improving crop tolerance and weed suppressive ability may be beneficial to an integrated weed management program. Several authors have examined interactions between herbicide dose and weed suppressive ability among small grain cultivars and suggested that combining reduced doses of herbicide with competitive cultivars may reduce seedbank growth rate (Christensen 1994; Lemerle et al. 1996; Salonen 1992). Such an approach is desirable because it may reduce the cost of herbicide application, as well as the total quantity of herbicide applied. Research to examine the interaction between competitive corn canopies and herbicide dose may also be warranted.

\section{Sources of Materials}

${ }^{1}$ All four hybrids were produced by Pioneer Hi-Bred International, Inc., P.O. Box 14453, Des Moines, IA 50306-3453.

2 Case 900 Cycloair planter, Case Corp., 700 State St., Racine, WI 53404 .

${ }^{3}$ LI-3100, LiCor Inc., 4421 Superior St., Lincoln NE 68504.

${ }^{4}$ LI-190SA, LiCor Inc., 4421 Superior St., Lincoln NE 68504.

${ }^{5}$ LI-191SA, LiCor Inc., 4421 Superior St., Lincoln NE 68504.

\section{Acknowledgments}

This research was supported in part by USDA/CSRS National Research Initiative Competitive Grant 95-37315-2049. We thank D. Duvick for providing seed of Pioneer Brands 336 and 344 . Paper 12019, J. Ser., Nebraska Agricultural Research Division, University of Nebraska.

\section{Literature Cited}

Berkowitz, A. R. 1988. Competition for resources in weed-crop mixtures. Pages 89-120 in M. A. Altieri and M. Liebman, eds. Weed Management in Agroecosystems: Ecological Approaches. Boca Raton, FL: CRC Press.

Callaway, M. B. 1990. A compendium of crop varietal tolerance to weeds. Am. J. Alternative Agric. 7:169-180.

Callaway, M. B. and F. Forcella. 1992. Crop tolerance to weeds. Pages 100131 in M. B. Callaway and C. A. Francis, eds. Crop Improvement for Sustainable Agriculture Systems. Lincoln NE: University of $\mathrm{Ne}$ braska Press.

Christensen, S. 1994. Crop weed competition and herbicide performance in cereal species and varieties. Weed Res. 34:29-36.

Cousens, R. 1985. A simple model relating yield loss to weed density. Ann. Appl. Biol. 107:239-252.

Cousens, R. D. and D. J. Fletcher. 1990. Experimental design for screening competitiveness of crop cultivars. Pages 163-165 in Proceedings of the 9th Australian Weeds Conf. Adelaide, S. Australia: Crop Science Society of Australia, with assistance from the Wheat Research Council of Australia.

Duvick, D. N. 1992. Genetic contributions to advances in yield of U.S. maize. Maydica 37:69-79.

Forcella, F. 1987. Tolerance of weed competition associated with high leaf area expansion rate in tall fescue. Crop Sci. 27:146- 147.

Jennings, P. R. and R. C. Aquino. 1968. Studies on competition in rice. III. Mechanisms of competition among phenotypes. Evolution 22: $529-542$.

Jordan, N. 1993. Prospects for weed control through crop interference. Ecol. Appl. 3:84-91. 
Kropff, M. J. and H. H. van Laar. 1993. Modelling crop-weed interactions. Wallingford, Great Britain: CAB International and the International Rice Research Institute. $274 \mathrm{p}$.

Lemerle, D., B. Verbeek, and N. E. Coombes. 1996. Interaction between wheat (Triticum aestivum) and diclofop to reduce the cost of annual ryegrass (Lolium rigidum) control. Weed Sci. 44:634-639.

Levitt, J. 1980. Response of plants to environmental stresses. 2nd ed, Volume 2. New York: Academic Press. 607 p.

Lindquist, J. L. 1997. An Ecophysiological Approach to Understanding Corn Tolerance and Velvetleaf Suppressive Ability. Ph.D. thesis. University of Nebraska, Lincoln, NE. 156 p.

Lindquist, J. L. and M. J. Kropff. 1996. Applications of an ecophysiological model for irrigated rice (Oryza sativa) - Echinochloa competition. Weed Sci. 44:52-56.

Lindquist, J. L., D. A. Mortensen, S. A. Clay, R. Schmenk, J. J. Kells, K. Howatt, and P. Westra. 1996. Stability of corn (Zea mays)-velvetleaf (Abutilon theophrasti) interference relationships. Weed Sci. 44:309313.

Lindquist, J. L., D. A. Mortensen, and B. E. Johnson. 1998. Mechanisms of corn tolerance and velvetleaf suppressive ability. Agron. J. In press.

Lotz, L.A.P., S. Christensen, D. Cloutier, et al. 1996. Prediction of the competitive effects of weeds on crop yields based on the relative leaf area of weeds. Weed Res. 36:93-101.

McLachlan, S. M., M. Tollenaar, C. J. Swanton, and S. F. Weise. 1993. Effect of corn-induced shading on dry matter accumulation, distribution, and architecture of redroot pigweed (Amaranthus retroflexus). Weed Sci. 41:568-573.

Murphy, S. D., Y. Yakubu, S. F. Weise, and C. J. Swanton. 1996. Effect of planting patterns and inter-row cultivation on competition between corn (Zea mays) and late emerging weeds. Weed Sci. 44:856-870.

Ottman, M. J. and L. F. Welch. 1989. Planting patterns and radiation interception, plant nutrient concentration, and yield in corn. Agron. J. 81:167-174.

Ratkowsky, D. A. 1983. Nonlinear regression modeling: a unified practical approach. New York: Marcel Dekker. 276 p.

Salonen, J. 1992. Efficacy of reduced herbicide doses in spring cereals of different competitive ability. Weed Res. 32:483-491.

Staniforth, D. W. 1961. Responses of corn hybrids to yellow foxtail competition. Weeds 9:132-136.

Swinton, S. M., D. D. Buhler, F. Forcella, J. L. Gunsolus, and R. P. King. 1994. Estimation of crop yield loss due to interference by multiple weed species. Weed Sci. 42:103-109.

Tetio-Kagho, F. and F. P. Gardner. 1988. Responses of maize to plant population density. I. Canopy development, light relationships, and vegetative growth. Agron. J. 80:930-935.

Tollenaar, M., A. A. Dibo, A. Aguilera, S. F. Wiese, and C. J. Swanton. 1994a. Effect of crop density on weed interference in maize. Agron. J. 86:591-595.

Tollenaar, M., S. P. Nissanka, A. Aguilera, S. F. Weise, and C. J. Swanton. $1994 \mathrm{~b}$. Effect of weed interference and soil nitrogen on four maize hybrids. Agron. J. 86:596-601.

Tollenaar, M., A. Aguilera, and S. P. Nissanka. 1997. Grain yield is reduced more by weed interference in an old than in a new maize hybrid. Agron. J. 89:239-246.

Wicks, G. A., R. E. Ramsel, P. T. Nordquist, J. W. Schmidt, and Challaiah. 1986. Impact of wheat cultivars on establishment and suppression of summer annual weeds. Agron. J. 78:59-62.

Williams, W. A., R. S. Loomis, W. G. Duncan, A. Dovrat, and F. Nunez A. 1968. Canopy architecture at various population densities and the growth and grain yield of corn. Crop Sci. 8:303-308.

Received September 2, 1997, and approved June 16, 1998. 